\title{
Article
}

\section{Designing Online Platforms Supporting Emotions and Awareness}

\author{
César A. Collazos ${ }^{1}\left[\right.$, Habib Fardoun ${ }^{2,3}\left[\mathbb{\infty}\right.$, Deema AlSekait ${ }^{4}$, Carla Santos Pereira ${ }^{5}\left(\mathbb{D}\right.$ and Fernando Moreira ${ }^{5,6, *}$ \\ 1 IDIS Research Group, Universidad del Cauca, Popayán 190001, Colombia; ccollazo@unicauca.edu.co \\ 2 Information Systems Department, King Abdulaziz University, Jeddah 21589, Saudi Arabia; \\ hfardoun@kau.edu.sa \\ 3 Education Department, Ahlia University, Manama 10878, Bahrain \\ 4 Department of Computer Science \& Information Systems, Princess Nourah bint Abdulrahman University, \\ Riyadh 11671, Saudi Arabia; DMAlSekait@pnu.edu.sa \\ 5 REMIT, Universidade Portucalense, 4200-072 Porto, Portugal; carlasantos@uportu.pt \\ 6 IEETA, Universidade de Aveiro, 3810-193 Aveiro, Portugal \\ * Correspondence: fmoreira@upt.pt
}

Citation: Collazos, C.A.; Fardoun, H.; AlSekait, D.; Pereira, C.S.; Moreira, F. Designing Online Platforms Supporting Emotions and Awareness. Electronics 2021, 10, 251. https://doi.org/10.3390/ electronics10030251

Academic Editor: Christos J. Bouras Received: 7 January 2021

Accepted: 19 January 2021

Published: 22 January 2021

Publisher's Note: MDPI stays neutral with regard to jurisdictional claims in published maps and institutional affiliations.

Copyright: (c) 2021 by the authors. Licensee MDPI, Basel, Switzerland. This article is an open access article distributed under the terms and conditions of the Creative Commons Attribution (CC BY) license (https:// creativecommons.org/licenses/by/ $4.0 /)$.

\begin{abstract}
Due to the global pandemic (COVID-19) currently facing humanity, a new environment that promotes teaching-learning is now emerging. This environment that challenges traditional teaching practices created an opportunity for the technology industry to capitalize on by developing creative e-learning platforms that empowers the teaching-learning process, during this 'emergency' situation. E-learning scenario is an important element to be considered, as it offers a host of benefits, such as reducing costs, allowing for education on-demand, etc., to its adopters. However, the application of this could bring some challenges, as some of the existing online platforms are not conducive to support clear communication among academic staff. This paper describes a report identifying the main problems faced by teachers and students from different countries in Latin America, when using e-learning platforms in a lockdown scenario, reporting the importance to include aspects related with emotions and awareness.
\end{abstract}

Keywords: awareness; emotion; design guidelines; online platforms; educational experience

\section{Introduction}

With recent social interactional changes caused by COVID-19, we find ourselves in an environment that promotes the integration of online and web-based communication tools and their application specifically in the world of teaching, education, and learning. Different online platforms supporting web-based education could provide the means to enhance communication between students and teachers through offering services such as chat tools, logs, forums, discussion boards, emails, improving teaching-learning processes. Kubala [1] have found that including some of these elements or services in an online course could increase students' participation, communication, collaboration, and motivation related to projects and class discussions. In that way, it is possible that students feel a greater willingness to participate and empowerment with their classroom activities [1]. These kind of platforms-online and web-based systems-are information systems that use Internet web technologies to deliver information and services supporting teachinglearning processes, have shown clear benefits like reduced costs, great flexibility for both students and teachers, and the possibility of simultaneously training numerous students from different parts of the world. The nature of online education can create a sense of isolation in students, where they can feel disconnected from the professor and the rest of their classmates. It is crucial that teachers monitoring the activities of their students at any given moment, thereby overcoming some of the challenges related to the inertia and passivity of traditional classroom courses.

Because of the situation around the world with COVID-19, many schools and higher education institutions-HIE, across many countries worldwide, had to pivot quickly to 
adopt virtual classrooms as a means of delivering education, in so-called emergency education. However, this transition has not been an easy task. Online training has specific characteristics that need to be considered in order to benefit from the education process. A convenient mechanism to realize the potential use of online learning is to check and review some problems found by other institutions around the world. Aspects related to awareness and emotions have been detected as one of the main problems in a survey we have conducted with professors and students with different Latin American institutions that will be depicted in a more detailed manner in Section 2 of this paper.

This paper provides a set of recommendations to design e-learning systems that allow teachers and students work in a better manner, through ensuring a good teaching-learning process, and improving communication. Section 2 describes a survey we conducted to report the main problems faced by teachers and students when using e-learning platforms in a lockdown scenario with some Latin American participants (both teachers and students). Section 3 depicts some related works focusing on the use of emotions and awareness in online learning. In Section 4, we propose a set of design guidelines that promotes a better interaction among teachers and students using web platforms in their teaching-learning process. Finally, we include some conclusions and further works in Section 5.

\section{Challenges in Using e-Learning Platforms}

We conducted a survey through online forms to obtain more information about the main problems encountered by people that had to use web-based and e-learning platforms for daily academic activities during the lockdown imposed in the face of the COVID-19 pandemic. The participants included 54 teachers of different academic programs of high school (17) and university (37) with ages from 30-50; and 42 students (28 of university and 14 of high school) with ages from 20-25 from diverse Latin-American countries, including Colombia, Chile, Perú, Brazil, Costa Rica, Argentina, and México.

Figures 1 and 2 depict information about the academic programs of both teachers and students from different Latin American Universities, where the major part belongs to Technical studies (Computer Science and Electronics Engineering).

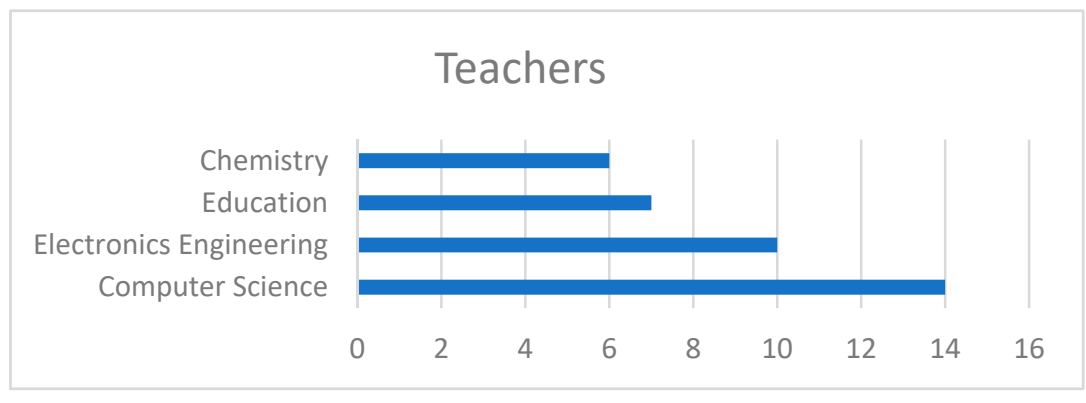

Figure 1. Teacher programs.

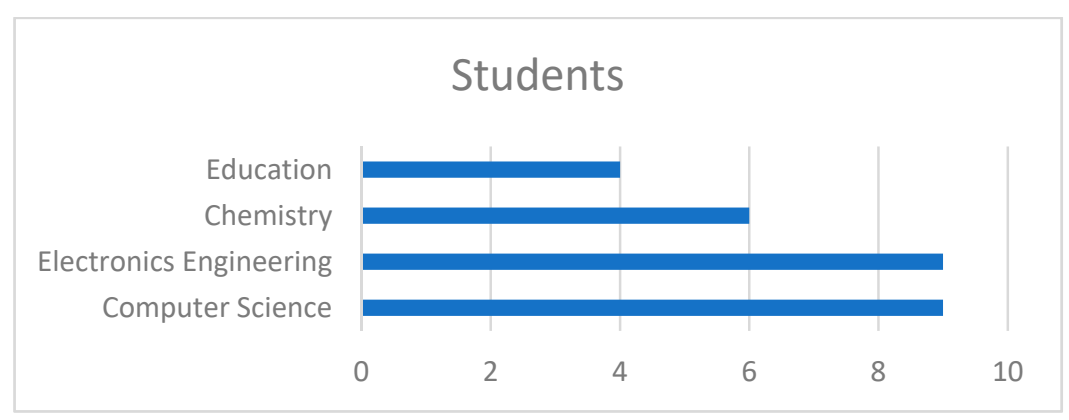

Figure 2. Student programs. 
All the surveyed participants were informed about the main goal of the study prior to conducting it and all consents were collected. The survey covered the following four questions:

1. What web or e-learning platform were the most used during lockdown?

2. What were the main problems in using the said platforms?

3. What were the main advantages in using the said platforms?

4. Once the lockdown is lifted, will you use these platforms again?

Figure 3 below shows the results for question 1. The results highlight how Zoom is the most used platform, and M. Teams (Microsoft Teams) is the least used one for both teachers and students.

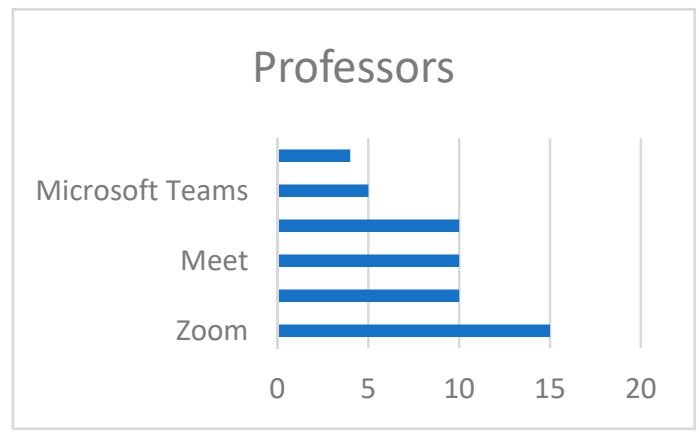

(a)

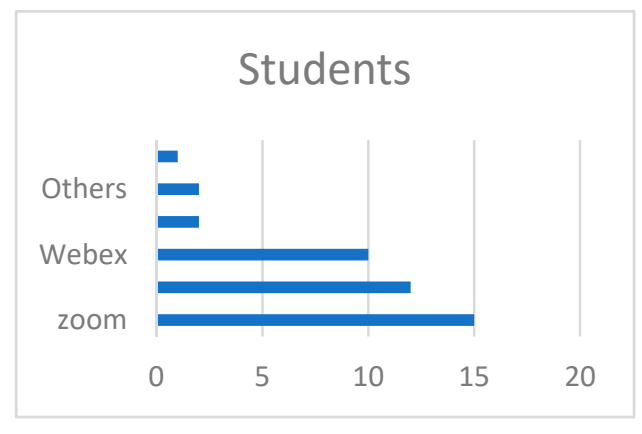

(b)

Figure 3. Web platforms usage by teachers (a) and students (b).

The non-parametric Mann-Whitney test allowed (Table 1) us to conclude that there were no significant and important differences between the use of the various platforms by students and teachers (variable - role) at a significance level of $5 \%$ ( $p$-value $=0.129>0.05)$.

Table 1. Mann-Whitney test for web platforms, by role

\begin{tabular}{cc}
\hline & Test Statistics $^{\text {a }}$ \\
\hline & What Web or e-Learning Platform Were the Most Used During Lockdown? $^{-}$ \\
Mann-Whitney U & 934.000 \\
Wilcoxon W & 2419.000 \\
Z & -1.518 \\
Asymp. Sig. (2-tailed) & 0.129 \\
\hline
\end{tabular}

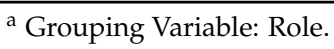

Respondents were asked to point out the five main problems encountered (first main problem to the fifth main problem). If instead of focusing only on the totality of the problems described, we analyze in detail which was the first problem pointed out, we obtain the result shown on Table 2.

From the results obtain and shown on Table 2, we conclude that the main problem pointed out was 'privacy' followed by 'bored scenarios' and 'slow connections'.

Doing this analysis separately for students and teachers (Figure 4), we found that for teachers, the main problem is 'privacy' (46\%) and for students 'bored scenarios' (33.3\%). Note that the problem 'interruptions' is not pointed out as the first main problem except for one teacher.

We analyzed whether there are significant differences in the responses given by teachers and students concerning the first main problem pointed out. Considering only the most pointed out as the main one, the Chi-square test (with all the assumptions applying the test verified) allowed us to summarize that there are significant differences at $10 \%$ $(p$-value $=0.076<10 \%)($ Table 3$)$. 
Table 2. Contingency table for variables role and first main problem

\begin{tabular}{|c|c|c|c|c|c|c|c|c|}
\hline \multicolumn{9}{|c|}{ Role by First Main Problem Cross Tabulation } \\
\hline \multicolumn{9}{|c|}{ Count } \\
\hline & \multicolumn{7}{|c|}{ First Main Problem } & \multirow[b]{2}{*}{ Total } \\
\hline & Privacy & $\begin{array}{c}\text { Slow } \\
\text { Connection }\end{array}$ & $\begin{array}{c}\text { Bored } \\
\text { Scenarios }\end{array}$ & $\begin{array}{c}\text { No } \\
\text { Feedback }\end{array}$ & $\begin{array}{c}\text { Lack of } \\
\text { Equipment }\end{array}$ & $\begin{array}{l}\text { Lack of Preparedness } \\
\text { to Use Technology }\end{array}$ & Interruptions & \\
\hline \multirow{2}{*}{ Role $\begin{array}{l}\text { student } \\
\text { teacher }\end{array}$} & 12 & 10 & 14 & 5 & 0 & 1 & 0 & 42 \\
\hline & 25 & 6 & 12 & 0 & 4 & 6 & 1 & 54 \\
\hline Total & 37 & 16 & 26 & 5 & 4 & 7 & 1 & 96 \\
\hline
\end{tabular}

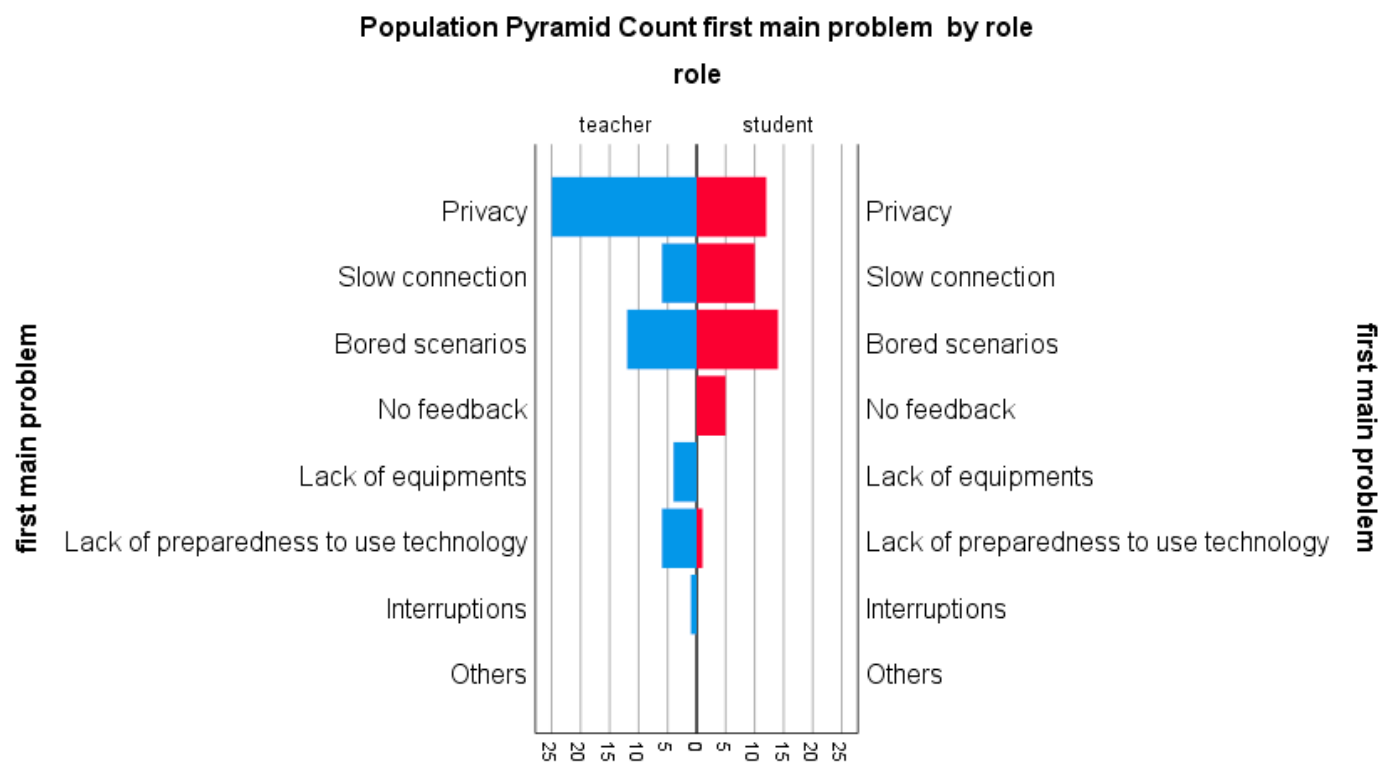

Figure 4. First main problems.

Table 3. Results of Chi-square test for variables role and first main problem.

\begin{tabular}{cccc}
\hline \multicolumn{4}{c}{ Chi-Square Tests } \\
\hline & Value & df & Asymptotic Significance (Two-Sided) \\
\hline Pearson Chi-Square & 5.142 & 2 & 0.076 \\
Likelihood Ratio & 5.210 & 2 & 0.074 \\
Linear-by-Linear Association & 3.185 & 1 & 0.074 \\
N of Valid Cases & 79 & - & - \\
\hline
\end{tabular}

Analyzing the cross-tabulation table in detail, we see that these differences exist because while the majority of teachers $(58.1 \%)$ pointed out 'privacy' as the first main problem and the main problem pointed out by the students was 'bored scenarios' (38.9\%), as shown on Table 4.

For both, teachers and students, some of the problems identified were related to absence of feedback, due to in many opportunities people do not know if there is anyone connected. Another aspect they mention as complicated, was related with bored scenarios. In a physical classroom setting, interactions are more dynamic, and course instructors can easily stimulate feedback from students. When speaking about online courses, Brunori states that teachers should seek creative ways to encourage students to ask questions and suggest new ideas since one of the main bottlenecks is the need for teachers to adapt their teaching methods to the instrument of teaching [2]. Lack of feedback makes its challenging for the teacher to adequately understand whether or not the audience has grasped the concepts being presented. This kind of problem requires a mechanism to 
provide information about who is in the classes and what are they doing; that way, aspects related with awareness will be included in the design guidelines that will be mentioned in next section.

Table 4. Cross tabulation for variables role and first main problem (with percentages by row and column).

\begin{tabular}{|c|c|c|c|c|c|c|}
\hline \multicolumn{7}{|c|}{ Role by First Main Problem Cross Tabulation } \\
\hline & & & \multicolumn{3}{|c|}{ First Main Problem } & \multirow{2}{*}{ Total } \\
\hline & & & Privacy & Slow Connection & Bored Scenarios & \\
\hline \multirow{6}{*}{ Role } & \multirow{3}{*}{ Student } & Count & 12 & 10 & 14 & 36 \\
\hline & & \% within role & $33.3 \%$ & $27.8 \%$ & $38.9 \%$ & $100.0 \%$ \\
\hline & & $\%$ within main problem & $32.4 \%$ & $62.5 \%$ & $53.8 \%$ & $45.6 \%$ \\
\hline & \multirow{3}{*}{ Teacher } & Count & 25 & 6 & 12 & 43 \\
\hline & & $\%$ within role & $58.1 \%$ & $14.0 \%$ & $27.9 \%$ & $100.0 \%$ \\
\hline & & $\%$ within main problem & $67.6 \%$ & $37.5 \%$ & $46.2 \%$ & $54.4 \%$ \\
\hline \multirow{3}{*}{\multicolumn{2}{|c|}{ Total }} & Count & 37 & 16 & 26 & 79 \\
\hline & & $\%$ within role & $46.8 \%$ & $20.3 \%$ & $32.9 \%$ & $100.0 \%$ \\
\hline & & $\%$ within main problem & $100.0 \%$ & $100.0 \%$ & $100.0 \%$ & $100.0 \%$ \\
\hline
\end{tabular}

Another problem identified in the survey was related to slow internet connections, with video feeds freezing, low bandwidth, and congested airways. This problem, may discourage users from using their cameras all the time during the online sessions, resulting in an interrupted learning experience.

With regard to the lack of equipment, some students mentioned that they did not have television and internet facilities at their homes. Some students and teachers do not have the minimal technical requirements to support e-learning, due in some cases to lack of access to basic infrastructure such as internet and electricity. Even if some of these problems related to access and connectivity were resolved, there remains the challenge of ensuring that students have an environment that adequately supports learning. Students reported that they need quiet spaces where they can participate in online classes without interruptions. This implies a continuous cooperation and participation of parents and teachers with the goal to create an effective learning scenario for students. This was a major challenge even during pre-lockdown times. Most teachers who were interviewed felt that it was too difficult to make some parents try to understand the importance of their involvement in the academic process.

Some teachers have mentioned the importance of knowledge on the use of technology in the teaching-learning process in order to ensure an effective education. In that way, it is necessary to have digital competencies in teachers and students in order to use in an appropriate manner technology. For that reason, the ability to use technology effectively is considered a key competency.

As with the main problems, respondents were also asked to point out the five main advantages found (first main advantage to the fifth main advantage). If instead of focusing only on the totality of the advantages mentioned, we now analyze in detail which was the first advantage pointed out, (Figure 5) we obtain:

The first advantage identified as the main one is 'provide technical and didactic support' followed by 'discover new resources' and finally 'availability'.

Chi-square nonparametric test (Table 5) to assess whether there are significant differences in opinions between students and teachers, as for the main advantage it indicates that there are statistical differences at 5\% ( $p$-value $=0.014<0.05)$. 


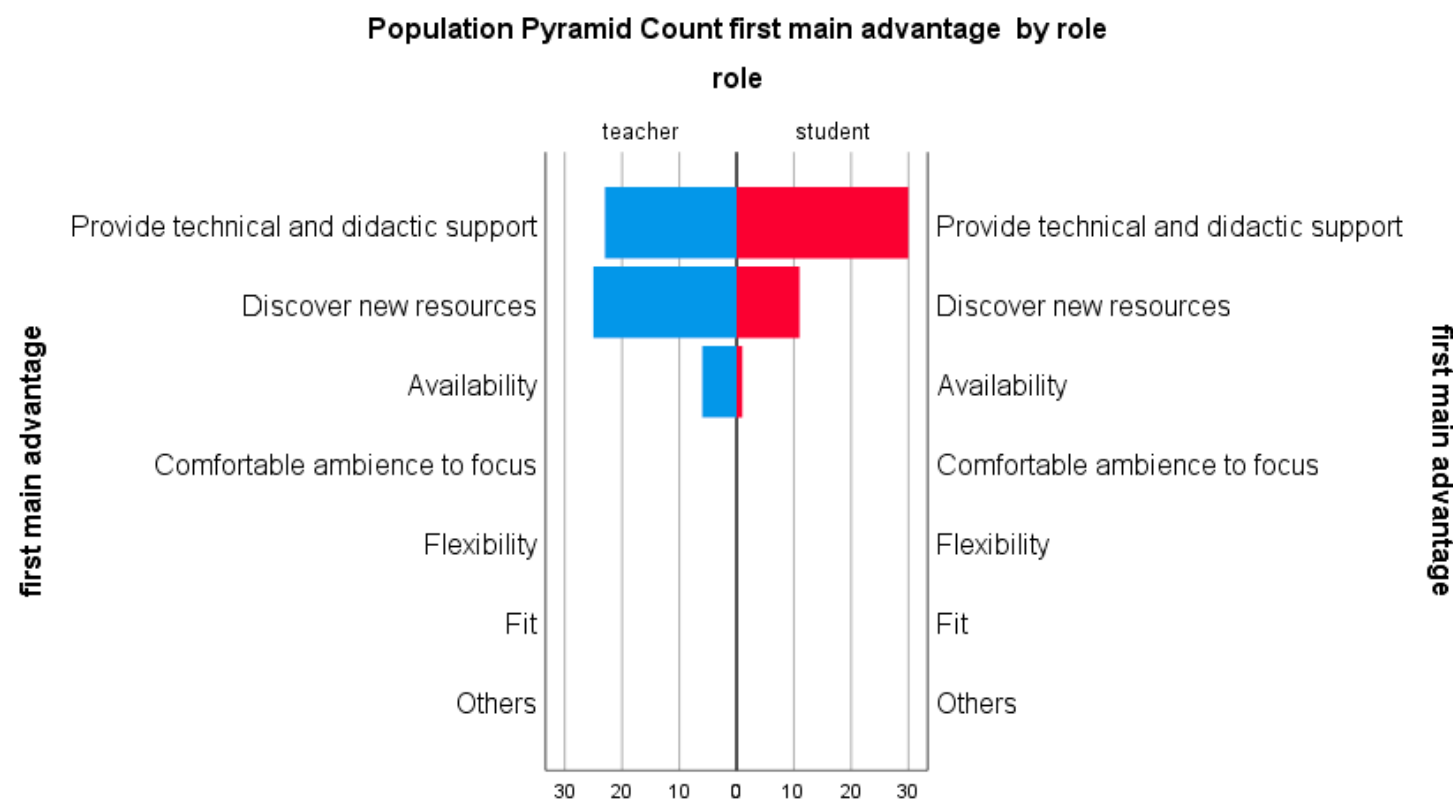

Figure 5. First main advantages.

Table 5. Results of Chi-square test for variables role and first main advantage

\begin{tabular}{cccc}
\hline & \multicolumn{3}{c}{ Chi-Square Tests } \\
\hline & Value & df & Asymptotic Significance (Two-Sided) \\
\hline Pearson Chi-Square & 8.574 & 2 & $\mathbf{0 . 0 1 4}$ \\
Likelihood Ratio & 8.976 & 2 & 0.011 \\
Linear-by-Linear Association & 8.344 & 1 & 0.004 \\
N of Valid Cases & 96 & - & - \\
\hline
\end{tabular}

The cross-tabulation table (Table 6) that crosses the two variables allows us to conclude that, while most teachers $(71.4 \%)$ point to 'provide technical and didactic support' as the most significant advantage, most students point to 'discover new resources' (46.3\%).

The responses obtained have shown us that online learning can be carried out asynchronously, in a way both teachers and students can work and contribute at times appropriate for them, and they do not have to be in a particular place at any specific time. This aspect brings some flexibility allowing teachers to balance their life at home with their responsibility at school. Additionally, online courses bring students the option to plan their study time, in a way they can attend the online courses at their convenience anytime and anywhere. In that way, students have the opportunity to study and work, giving time to analyze the study material, engage with each other, work, and perform their own research activities. It will bring an interaction opportunity with teachers anytime $(24 \times 7$ availability), clearing some doubts, taking tests.

Another important aspect that both teachers and students mentioned is related to the budget-friendliness of online learning. Currently, we find many online courses and resources for free access, thereby overcoming the limitations imposed by financial issues for fee payment during the lockdown time. Some students mentioned the opportunity to take classes in addition to the traditional ones. Online learning allows them to remain at home with their family, bringing many advantages over traditional teaching-learning scenarios, like saving money, saving time, and working anytime and anywhere.

Students interviewed also mentioned their feeling about the comfortable ambient on the learning process. With online learning, it is easier to focus on the teaching process. They can be in the right environment, using the most adequate elements depending of the situation (for example they can use headphones if the surroundings are noisy). They have the opportunity to communicate with their professors and with other students, discussing 
about a certain topic sending posts among them, and so, they are able to be more active participant. They have the opportunity to read, check and make suggestions to the work of their classmates, allowing them to learn through the sharing of messages examining their own perceptions about a topic. This makes class work more interesting and fun.

Table 6. Cross tabulation for variables role and first main advantage (with percentages by row and column)

\begin{tabular}{|c|c|c|c|c|c|c|}
\hline \multicolumn{7}{|c|}{ Role by First Main Advantage Cross Tabulation } \\
\hline & & & \multicolumn{3}{|c|}{ First Main Advantage } & \multirow[b]{2}{*}{ Total } \\
\hline & & & $\begin{array}{l}\text { Provide Technical and } \\
\text { Didactic Support }\end{array}$ & $\begin{array}{l}\text { Discover New } \\
\text { Resources }\end{array}$ & Availability & \\
\hline \multirow{6}{*}{ Role } & \multirow{3}{*}{ Student } & Count & 30 & 11 & 1 & 42 \\
\hline & & $\%$ within role & $71.4 \%$ & $26.2 \%$ & $2.4 \%$ & $100.0 \%$ \\
\hline & & $\%$ within main advantage & $56.6 \%$ & $30.6 \%$ & $14.3 \%$ & $43.8 \%$ \\
\hline & \multirow{3}{*}{ Teacher } & Count & 23 & 25 & 6 & 54 \\
\hline & & $\%$ within role & $42.6 \%$ & $46.3 \%$ & $11.1 \%$ & $100.0 \%$ \\
\hline & & $\%$ within main advantage & $43.4 \%$ & $69.4 \%$ & $85.7 \%$ & $56.3 \%$ \\
\hline \multirow{3}{*}{\multicolumn{2}{|c|}{ Total }} & Count & 53 & 36 & 7 & 96 \\
\hline & & $\%$ within role & $55.2 \%$ & $37.5 \%$ & $7.3 \%$ & $100.0 \%$ \\
\hline & & $\%$ within main advantage & $100.0 \%$ & $100.0 \%$ & $100.0 \%$ & $100.0 \%$ \\
\hline
\end{tabular}

We also decided to analyze whether there were differences in behavior between Colombia and other countries (variable 'country'). Having concluded, with the use of the Chi-square test (with validated test application assumptions), there are no significant differences concerning the platforms used. There are no significant differences with the main problem pointed out.

However, we conclude that there are significant differences, at a significance level of $5 \%$, concerning the main advantage pointed out $(p$-value $=0.044<0.05)($ Table 7$)$.

Table 7. Results of Chi-square test for variables role and country

\begin{tabular}{cccc}
\hline \multicolumn{4}{c}{ Chi-Square Tests } \\
\hline & Value & df & Asymptotic Significance (Two-Sided) \\
\hline Pearson Chi-Square & 6.259 a & 2 & 0.044 \\
Likelihood Ratio & 7.827 & 2 & 0.020 \\
Linear-by-Linear Association & 6.156 & 1 & 0.013 \\
N of Valid Cases & 96 & - & - \\
\hline a 1 cells (16.7\%) have expected count less than 5. The minimum expected count is 1.60.
\end{tabular}

Analyzing in more detail (Table 8), it appears that while the majority of Colombians (77.3\%) consider 'provide technical and didactic support' the biggest advantage, in other countries the opinion is less strong with this advantage (48.6\%) and competes with 'discover new resources' $(41.9 \%)$.

Perhaps it is also interesting for this analysis, to look at the frequency table that crosses the main problems pointed with the order in which they were identified (Table 9).

These results (Table 9) shown that privacy is the first problem followed by 'bored scenarios' and 'slow connection', the third 'no feedback' and finally 'interruptions'. Minor problems are related with 'lack of equipment' and 'lack of preparedness to use technology'.

Likewise, concerning the main advantages, the frequency table with the main problems pointed out in the order in which they were identified allows us to observe that the main advantage pointed out is 'provide technical and didactic support' followed by 'discover new resources'. As the second main advantage, 'availability' is indicated, followed by 'comfortable ambience to focus'. The third disadvantage is 'flexibility', and it is also pointed out as a 'fit' advantage (Table 10). 
Table 8. Cross tabulation for variables country and first main problem (with percentages by row and column)

\begin{tabular}{|c|c|c|c|c|c|c|}
\hline \multicolumn{7}{|c|}{ Country by First Main Advantage Cross Tabulation } \\
\hline & & & \multicolumn{3}{|c|}{ First Main Advantage } & \multirow[b]{2}{*}{ Total } \\
\hline & & & $\begin{array}{l}\text { Provide Technical and } \\
\text { Didactic Support }\end{array}$ & $\begin{array}{l}\text { Discover New } \\
\text { Resources }\end{array}$ & Availability & \\
\hline \multirow{6}{*}{ Country } & \multirow{3}{*}{ Colombia } & Count & 17 & 5 & 0 & 22 \\
\hline & & $\begin{array}{l}\text { \% within } \\
\text { country }\end{array}$ & $77.3 \%$ & $22.7 \%$ & $0.0 \%$ & $100.0 \%$ \\
\hline & & $\begin{array}{l}\% \text { within main } \\
\text { advantage }\end{array}$ & $32.1 \%$ & $13.9 \%$ & $0.0 \%$ & $22.9 \%$ \\
\hline & \multirow{3}{*}{$\begin{array}{l}\text { Another } \\
\text { countries }\end{array}$} & Count & 36 & 31 & 7 & 74 \\
\hline & & $\begin{array}{l}\text { \% within } \\
\text { country }\end{array}$ & $48.6 \%$ & $41.9 \%$ & $9.5 \%$ & $100.0 \%$ \\
\hline & & $\begin{array}{l}\% \text { within main } \\
\text { advantage }\end{array}$ & $67.9 \%$ & $86.1 \%$ & $100.0 \%$ & $77.1 \%$ \\
\hline \multirow{3}{*}{\multicolumn{2}{|c|}{ Total }} & Count & 53 & 36 & 7 & 96 \\
\hline & & $\begin{array}{l}\text { \% within } \\
\text { country }\end{array}$ & $55.2 \%$ & $37.5 \%$ & $7.3 \%$ & $100.0 \%$ \\
\hline & & $\begin{array}{l}\% \text { within main } \\
\text { advantage }\end{array}$ & $100.0 \%$ & $100.0 \%$ & $100.0 \%$ & $100.0 \%$ \\
\hline
\end{tabular}

Table 9. Frequency of each problem by choice order and by role

\begin{tabular}{|c|c|c|c|c|c|c|c|c|c|c|}
\hline & \multicolumn{2}{|c|}{$\begin{array}{l}\text { First Main } \\
\text { Problem }\end{array}$} & \multicolumn{2}{|c|}{$\begin{array}{l}\text { Second Main } \\
\text { Problem }\end{array}$} & \multicolumn{2}{|c|}{$\begin{array}{c}\text { Third Main } \\
\text { Problem }\end{array}$} & \multicolumn{2}{|c|}{$\begin{array}{l}\text { Fourth Main } \\
\text { Problem }\end{array}$} & \multicolumn{2}{|c|}{$\begin{array}{c}\text { Fifth Main } \\
\text { Problem }\end{array}$} \\
\hline & $S$ & $\mathbf{T}$ & $\mathbf{S}$ & $\mathbf{T}$ & $\mathbf{S}$ & $\mathbf{T}$ & $\mathbf{S}$ & $\mathbf{T}$ & $\mathbf{S}$ & $\mathbf{T}$ \\
\hline Privacy & 12 & 25 & 7 & 7 & 0 & 3 & - & - & - & - \\
\hline Bored scenarios & 14 & 12 & 17 & 13 & 9 & 1 & - & - & - & - \\
\hline Slow connection & 10 & 6 & 12 & 12 & 3 & 2 & - & - & - & - \\
\hline Interruptions & 1 & 0 & 0 & 15 & 0 & 3 & 12 & 17 & 24 & 3 \\
\hline No feedback & 5 & 0 & 5 & 0 & 30 & 0 & - & - & - & - \\
\hline Lack of equipment & 0 & 4 & 1 & 5 & 0 & 6 & 19 & 0 & - & - \\
\hline Lack of preparedness to use technology & 1 & 6 & 0 & 1 & 0 & 8 & 11 & 0 & - & - \\
\hline
\end{tabular}

S-Student; T-Teacher.

Table 10. Frequency of each advantage by choice order and by role

\begin{tabular}{|c|c|c|c|c|c|c|c|c|c|c|}
\hline & \multicolumn{2}{|c|}{$\begin{array}{l}\text { First Main } \\
\text { Advantage }\end{array}$} & \multicolumn{2}{|c|}{$\begin{array}{c}\text { Second Main } \\
\text { Advantage }\end{array}$} & \multicolumn{2}{|c|}{$\begin{array}{l}\text { Third Main } \\
\text { Advantage }\end{array}$} & \multicolumn{2}{|c|}{$\begin{array}{c}\text { Fourth Main } \\
\text { Advantage }\end{array}$} & \multicolumn{2}{|c|}{$\begin{array}{l}\text { Fifth Main } \\
\text { Advantage }\end{array}$} \\
\hline & $\mathbf{S}$ & $\mathbf{T}$ & $\mathbf{S}$ & $\mathbf{T}$ & $\mathbf{S}$ & $\mathbf{T}$ & $\mathbf{S}$ & $\mathbf{T}$ & $\mathbf{S}$ & $\mathbf{T}$ \\
\hline Provide technical and didactic support & 30 & 23 & - & - & - & - & - & - & - & - \\
\hline Discover new resources & 11 & 25 & 9 & 0 & - & - & - & - & - & - \\
\hline Availability & 1 & 6 & 31 & 26 & 8 & 0 & - & - & - & - \\
\hline Comfortable ambience to focus & - & - & 1 & 23 & 18 & 2 & 1 & 0 & - & - \\
\hline Fit & - & - & 1 & 3 & 6 & 3 & 10 & 12 & 6 & 0 \\
\hline Flexibility & - & - & - & - & 9 & 30 & 18 & 0 & 18 & 0 \\
\hline
\end{tabular}

Finally, students argued the convenience of fitting the classes into their day. Online classes can be scheduled according their existing responsibilities, allowing them to organize their study time and they can learn at their own pace and time. This means the classes impose much less pressure on the students and are less intense.

Figure $6 a, b$ shows the main results for the fourth question.

Figure $6 a, b$ shows that almost all the participants (teachers and students) responded that they prefer to continue using e-learning platforms despite the problems encountered. However, some mistakes need to be corrected. Although the shift to online education will bring a large number of opportunities, also implies some challenges. Some teachers and 
students will have a set of tools, resources, and methodological approaches to improve their teaching-learning processes. These online scenarios will bring the opportunity to be connected with their families, primordial aspect in the case of younger students, where is necessary a greater involvement of parents in the learning process.

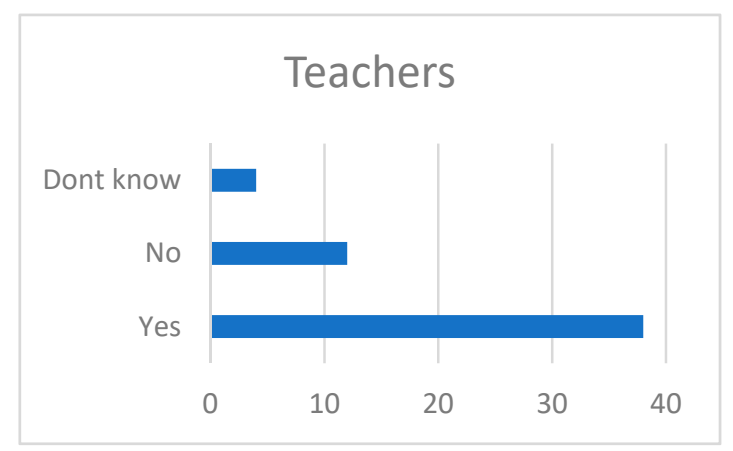

(a)

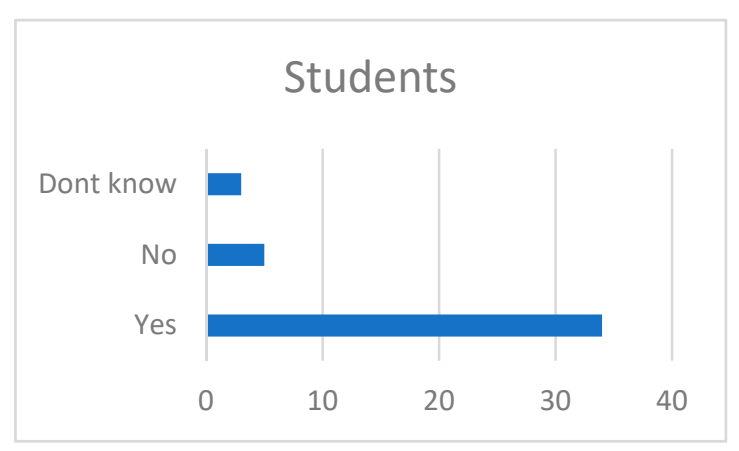

(b)

Figure 6. Teachers' (a) and students' (b) perspective of future use of e-learning platforms.

We also can conclude that for the future use of e-learning platforms, after removing the seven individuals who have not yet decided, the Chi-square test with continuity correction (suitable for $2 \times 2$ tables) (Table 11) lead us to summarize that there are no significant differences, at a level of significance of $5 \%$, in terms of the opinion from students and teachers regarding the future use of platforms (identical opinions, $p$-value $=0.162$ ). Considering the results already presented, it is concluded that both (teachers-70.4\% and students-83.3\%) intend to continue using these platforms.

Table 11. Results of Chi-square test for variables role and future use of platforms

\begin{tabular}{ccccc}
\hline & & & Chi-Square Tests \\
\hline & Value & df & $\begin{array}{c}\text { Asymptotic Significance } \\
\text { (Two-Sided) }\end{array}$ & $\begin{array}{c}\text { Exact Sig. } \\
\text { (Two-Sided) }\end{array}$ \\
\hline Pearson Chi-Square & $2.807^{\mathrm{a}}$ & 1 & 0.094 & - \\
(One-Sided) & - & - \\
Continuity Correction $b$ & 1.952 & 1 & 0.162 & - \\
Likelihood Ratio & 2.946 & 1 & - & - \\
Fisher's Exact Test & - & - & 0.096 & - \\
Linear-by-Linear Association & 2.775 & 1 & - & - \\
N of Valid Cases & 89 & - & - \\
\hline
\end{tabular}

${ }^{\text {a }} 0$ cells $(0.0 \%)$ have expected count less than 5 . The minimum expected count is 7.01 ; ${ }^{b}$ Computed only for a $2 \times 2$ table.

\section{Related Works}

The consideration of emotion and awareness in learning have been in the research agenda for quite long time and literature is offering a variety of studies that are evaluating the role of these important aspects in various learning contexts (class, test and exams, during studying at home, etc.). On this section, we first explore some works using awareness into the web/online platforms. Then we describe related works about the importance of emotions to improve communication in the teaching-learning process. The inclusion of emotion and awareness features in learning environments, could improve engagement of students enhancing their social interaction. The adoption of emotion and awareness features in learning environments, has been put on the focus of the research agenda towards students' engagement and their authentic social interaction. 


\subsection{Awareness}

One of the principal problems that the teacher must resolve in order to have a better learning experience using web platforms consists of identifying when and how to intervene [3]. It is mandatory for the teacher to know what the students are doing, with whom they are communicating, and so, trying to influence the individual learning and the acquisition of collaborative skills, like give and receive, define strategies, help, receive feedback, solve conflicts, and disagreements [4]. It is important to mention that trying to determine how and when to intervene, is as important as how to evaluate. If we have scenarios where teachers are collaborating with a lot of students in the same class at the same time, trying to determine how to evaluate and how to intervene, could be difficult to realize in an efficient manner if they are managed in a manual manner. In that way, aspects related with awareness implemented in online platforms could be a good help mechanism.

In that way, consider including aspects related with awareness could be beneficial. Group awareness is an important topic related to web-learning platforms. A teacher or a student should be aware of the teaching-learning process, being aware of almost all activities of the other members of the group to support learning processes effectively. These awareness mechanisms could be essential to improve group interactions. If professors and students are aware of what is happening around them, it is possible to promote interactions among the group members.

Increment into learners' interactions can trigger in better learning mechanisms. It is important that every member of the group should be aware of the actions, activities, and location of the other group members. For example, if one of the participants makes a mistake, it is necessary to have communication mechanisms helps the group members to make strategic decisions and modify and change their knowledge about the problem they have had. Thus, if there is more communication, there is a greater chance that the members collaborate, improving the learning process.

If professors have access to accurate data about the students, could reduce teachinglearning problems. As Ogan mentions [5], influencing what the student does is so important, to detect and intervene in an appropriate manner. If professor knows that a learner is bored, maybe they can have the opportunity to modify the activity or adjust the problem they are working with in a way that makes students feel more motivated. If we can sense the right misunderstanding student is having, it could be possible give them a different explanation of the topic in a way students can find a new route to discover the problem. If teachers have the option to know that a student is low in confidence, maybe they can offer some assurances and build trust with a mentoring relationship. Continuously, teachers are observing what the students are doing, to give some advice to support the learning process.

Different types of awareness in teaching-learning processes have been extensively studied: Collazos et al. identified knowledge awareness [6], and Goldman, concept, task, and social awareness [7]. Collazos et al. [8], have defined a specific taxonomy for depict awareness information (see Table 12). The taxonomy includes information about three main components of awareness: people, task or project, and resources. Each component has properties such as structure, state and location (people and resources) and structure, state (task or project).

Table 12. Awareness taxonomy.

\begin{tabular}{ccc}
\hline Components & Attribute & Supports \\
\hline \multirow{2}{*}{ 1. People } & 1. Structure & 2. State \\
& 3. Location & Social norms, conventions, roles \\
& Availability, activity, emotions \\
2. Structure & 2. State & Presence, distance, visibility, space-place, metaphors. \\
\hline \multirow{2}{*}{ Task or project } & 1. Structure & State-based workflow \\
& 2. State & Spatial, semantic networks \\
& 3. Location & Availability \\
\end{tabular}




\subsection{Emotions}

Another important element in online systems is related to emotions. The emotions of learners have an important impact on teaching-learning processes in classrooms [9]. Positive emotions, and like curiosity, enjoyment could influence the learning in a positive manner because emotions can help students to focus more on the activities, fostering their motivation to learn [10]. In contrast, negative emotions can have fatal consequences because they can guide the students attention far away from the activity they are working on, consuming extra cognitive resources, decreasing their performance on learning tasks [11]. Emotions can imply the presence of complex aspects of learning tasks that require attention and extra effort to accomplish the activity [12]. In that way, is a challenge, trying to develop an awareness of students' emotions in online learning/web scenarios settings. In online scenarios, where many of interactions are mediated (sometimes in an asynchronous manner), there are few spaces for informal exchanges can help professors develop an awareness of the students' emotions [13].

Emotion awareness and affective feedback appear as vital element could influence teaching-learning process $[14,15]$. Some authors have designed mechanisms providing agents supporting reflective learning in teaching-learning scenarios. For example, Daradoumis et al. [16] have proposed a study using an Affective Pedagogical Agent-APT, offering affective feedback to foster self-reflection into students about what and how they had learned. Arguedas et al. [17] have analyzed some consequences of emotion awareness, on students' motivation, engagement, self-regulation, and learning outcome in long-term blended collaborative learning practices. It is important to mention, based on emotion awareness information, professor could provide affective feedback ensuring in that way positive emotions into students, improving their learning experience [15]. Adequate feedback can cause a positive shift in the emotional state of students, redirecting their focus of attention inducing a change in the way they think, act, and interact with others, fostering their teaching-learning process [18].

As some of the works described in the literature presented, elements related with awareness and emotions are too important in learning situations could play a key role in decision-making processes. For that reason, these elements need to be considered in the design of online platforms supporting a better teaching-learning process. Next section describes the model we have designed to provide components of awareness and emotions.

\section{Design Guidelines}

The model we propose includes a set of design guidelines to implement more usable web-learning systems, leading to a better user (professors and students) acceptance. These guidelines focus on aspects related to awareness and emotions and could be implemented in synchronous scenarios.

We propose a set of guidelines denoted using the following notations: DGi, $\mathrm{j}, \mathrm{k}$, where $\mathrm{i}$ corresponds to every awareness component (1: People; 2: Task; 3: Resources); j denotes the specific attribute (For social, there are three attributes: structure, state, and location; for tasks, there are two attributes: structure and state; and for resources, there are three attributes: structure, state, and location); and $\mathrm{k}$ denotes the specific guideline proposed. Thus, DG1, 1, 1 will specify "Design Guideline Number 1" for the attribute "structure" of the component "People." On these lines, we propose the following guidelines:

DG1, 1, 1: Organization Chart: Knowing the workplace learning is one of the most important aspects need to be considered. This guideline allows us to identify the type of community of the people: family, work team, club member, etc. The participation may differ depending on the group, for example, when people are working with classmates as compared with when people are working with their professor or with someone who belongs to the administrative staff of an institution.

DG1, 1, 2: Avatars: It is known that e-learning scenarios where courses are interactive and immersive could be more effective than those that designed in astatic or solely contentdriven way. In fact, it could be possible use multiple avatars to take different roles (an 
avatar to represent the role of professor, and another to offer help about the topic of the activity to the students). An avatar is a representation of a particular well-defined entity. It is the way people are shown in a system, or rather, the way they want to be perceived by other people. Some avatars are sophisticated in the sense they may transmit emotions through graphic transformations. Nevertheless, the simplest way to transmit emotions is through emoticons, which are small images (icons) representing emotions. Emoticons have gained much popularity in recent online messaging systems.

DG1, 1, 3: Relationships: The local processes of participation through which relationships are shaped are explained by Lave and Wenger [19] through the concept of they have called "legitimate peripheral participation". This definition describes how the learning processes for students take place within communities of practice. Figure 5 shows a depiction of the type of relationships among participants, where the black lines represent strong relationships and the green ones, weak or new relationships (Figure 7).

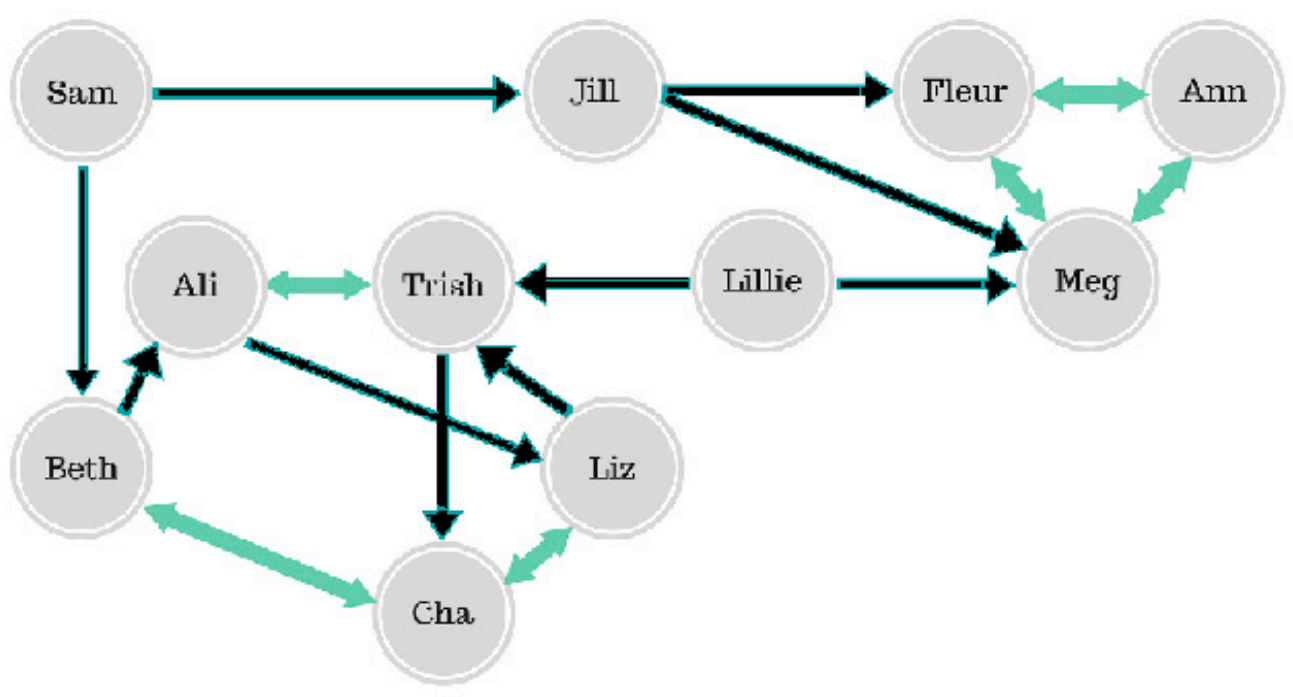

Figure 7. Relationship guideline.

DG1, 2, 1: Availability: It is important to know how the different resources have been used. A state describes the condition of an element. This guideline lets others know if a user is available to communicate with and at what level. Figure 8 shows the modes we propose (Figure 6).

DG1, 2, 2: Activity: This guideline represents a stage and depicts what the user is doing. Icons or phrases may be used to represent the users' activity (for example: reading, painting, and typing). Some examples of such representations are shown in Figure 9.

DG1, 2, 3: Emotion: Emotions can affect students and professors at different stages of the teaching-learning process. Emotions can influence, motivation, learning strategies, and ability to self-regulate learning. This guideline proposes to use mechanisms to represent user emotions (e.g., 'the user is sad'), such as the mechanism used in PrEmo. This guideline is shown in Figure 10.

D1, 3, 1: Presence: This aspect refers to the location inside or outside of the virtual shared space. There are some concepts related with such location: presence-being there; and co-presence-being together [21]. In this guideline, we propose the use of elements like telepointers (see Figure 11). Here, there are two users (Gizmo and Spike), and each of one is represented by a telepointer, gray for Spike and red for Gizmo. 


\begin{tabular}{ll}
\hline Available & Available \\
\hline Busy & Available, Out of Office \\
\hline Busy & On a call \\
\hline Do not disturb & O On a call, out of office \\
\hline Away & $\odot$ Presenting \\
\hline Be right back & $\odot$ Focusing \\
\hline A Away \\
\hline Away Last Seen time \\
\hline
\end{tabular}

Figure 8. Availability guideline.

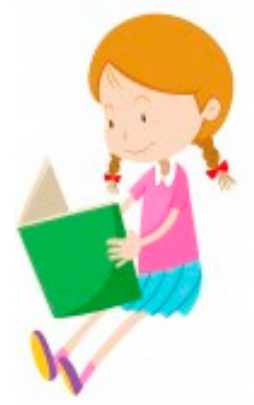

(a)

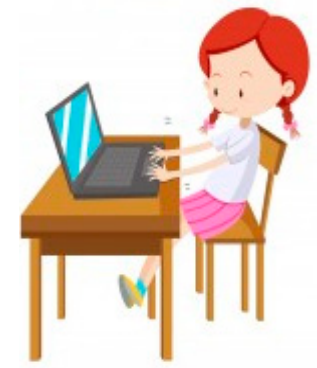

(b)

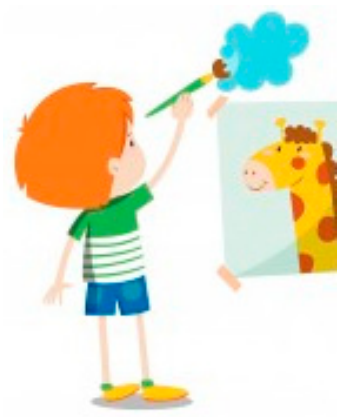

(c)

Figure 9. Activity guideline. (a) reading (b) typing (c) painting. 
Fascination, Joy, Happiness, Admiration, Pride, Satisfaction, Desire, Disgust, Anger, Disappointment, Shame, Fear, Sadness and Boredom

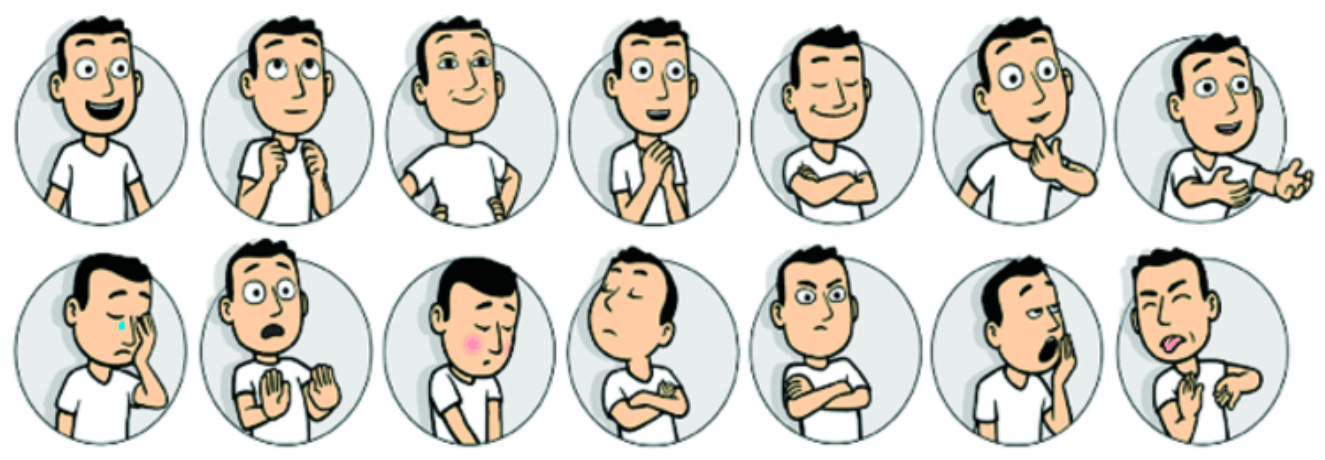

Figure 10. Emotion guideline [20].

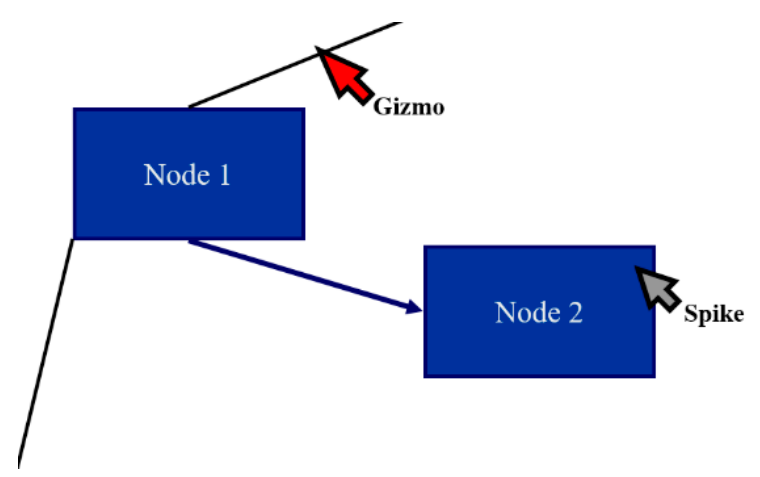

Figure 11. Presence guideline.

D1, 3, 2: Distance: The distance between group members (e.g., physical, social, and semantic distance) is an important factor. We propose using a mechanism like that proposed by Rodenstein- "Talking in Circles" [22], where group members communicate through speech, where they depicted as colored circles in a two-dimensional space. The different circles act as cues of presence and give some information about membership and activity in various conversations. Every time as one participant speak, a brighter inner circle appears modifying its radius according to the energy of their speech. Figure 12 shows an example of these awareness mechanisms.

D1, 3, 3: Visibility: These aspects refer to uses' device connection type (see Figure 11). We propose displaying information about the device used to have a better communication between the teacher and students. In addition, depending on the device configuration, information can be represented or visualized in a different manner. The information we recommend is depicted in Figure 13. 


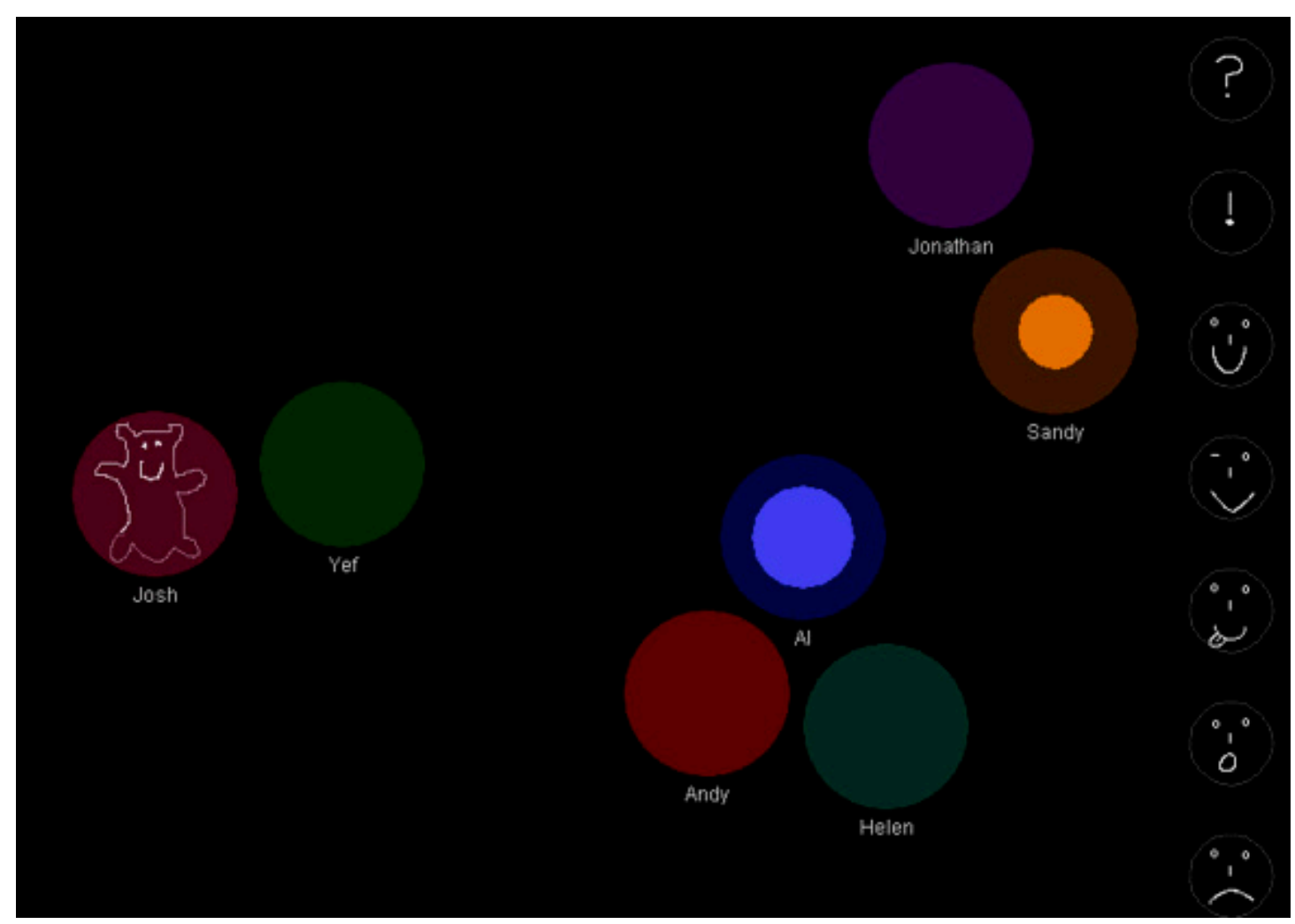

Figure 12. Distance guideline.

Device: Mobile, PC, Tablet, other

RAM:

\section{CPU Speed:}

Figure 13. Visibility guideline.

D2, 1, 1: Process Planning: Workflow is an important element in the acquisition of knowledge in the teaching-learning process. Information about what people is doing, tasks need to be performed, schedule, are elements need to be considered to regulate student and teacher interaction. In that way, it is necessary to have a mechanism allow them to be aware of the task structure. Gantt charts too can be used. Figure 14 shows a way to include this aspect.

D3, 1, 1: Semantic networks: in a teaching-learning scenario is too important to bring professors and students general information about where are people, resources, tasks, and activities, as a means for interpreting the relationships among different resources. On this guideline, we propose using conceptual maps, radar views, and versions for this purpose (Figure 15).

D3, 1, 2: Task participation: To know the level of participation of different group member is a teaching-learning activity is an important issue to bring more information about what they need to do. These mechanisms are developed for providing information about the level of participation of students. We recommend using mechanisms such as the "participameter" and "contribution meter" [23] (Figure 16). 


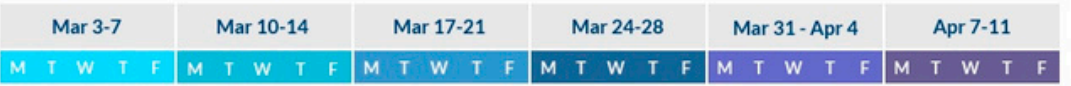

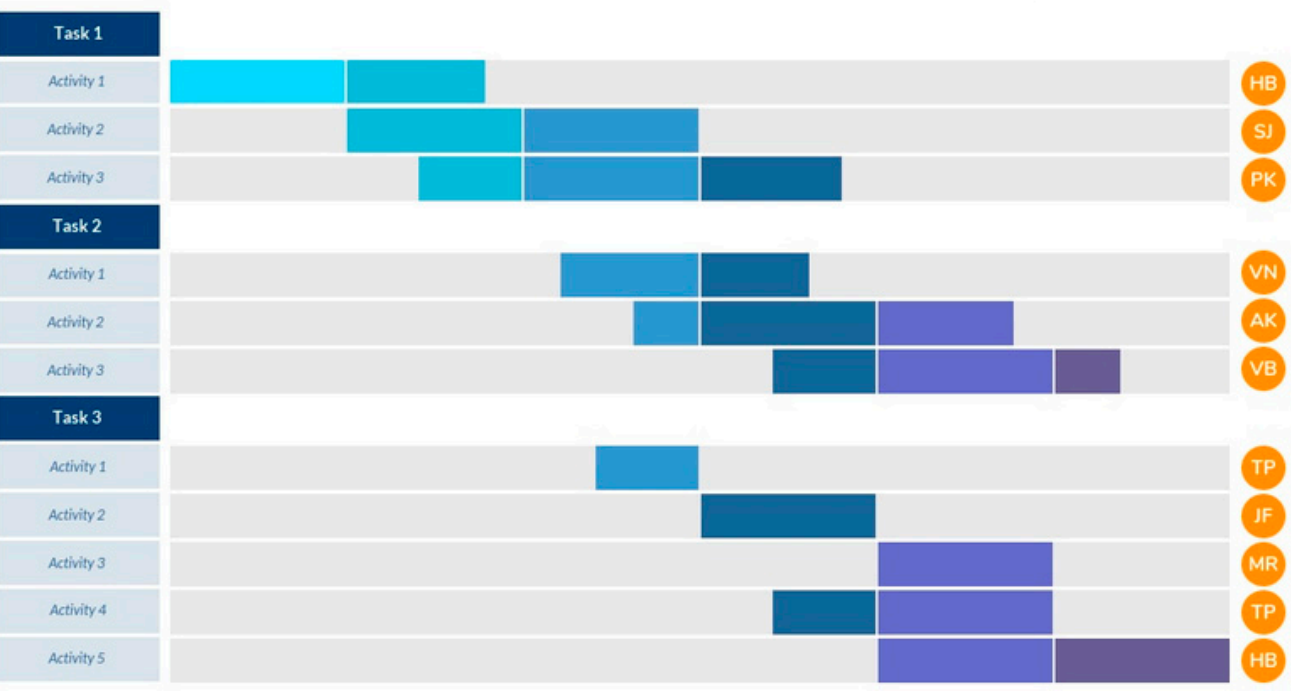

Figure 14. Process planning guideline.

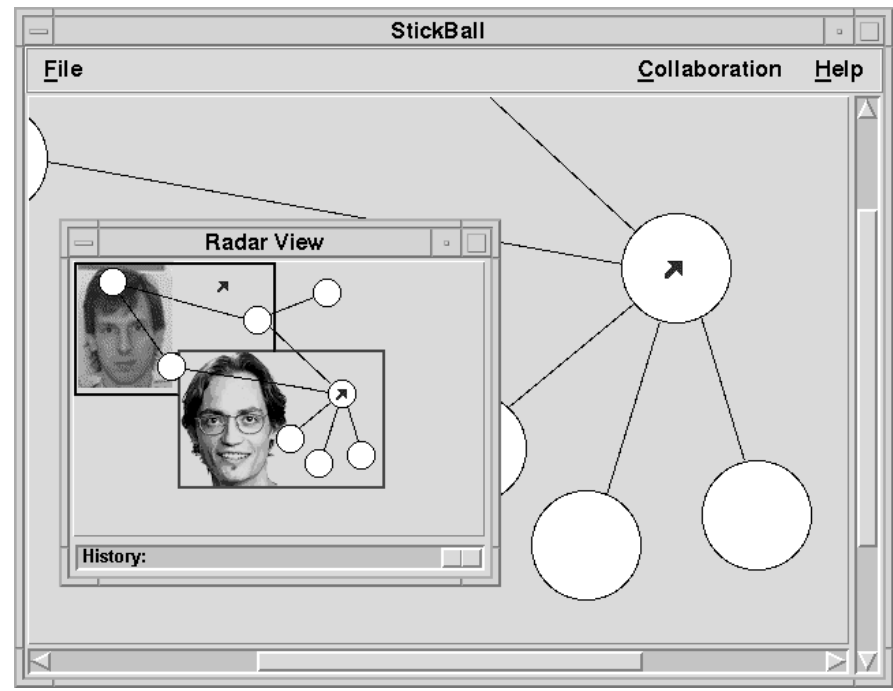

Figure 15. Spatial and semantic network guideline.

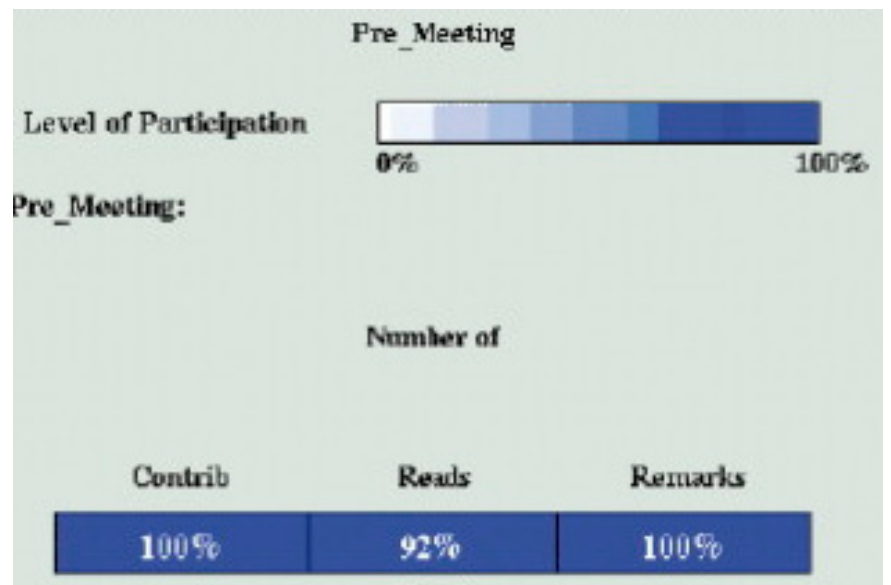

Figure 16. Participameter [18]. 
D3, 2, 1: Availability: Resources may be in a shared environment, which may be considered a common spatial frame inhabited by objects, representing people, information, artifacts, etc. For instance, virtual rooms [24] allow users to access to a set of predefined tools and information contained in a 'room'.

D3, 3, 1: Resource: These aspects refer to the shared resources available for executing a task. We recommend providing present information about the resources (tools, materials, skills, and expertise) needed to complete the task.

These guidelines we have proposed to be consider in online-web platforms allowing a better communication among teachers and students have been validated with several web designers. We interviewed 30 people in different Latin American countries, where they manifested the importance of having these guidelines. They manifested the guidelines proposed allow to think how the web platforms must be designed in a way people (students and teachers) feel part of a group, and so, participate in a better manner, improving the teaching-learning processes. People surveyed considered design online/web platforms supporting teaching-learning process is not an easy task. Emotions and awareness are important issues in the process design, but there are other elements, like gender, culture, age, personality, need to be considered. In that way, as the cybergogy model propose it could be convenient to integrate cognitive, emotive, and social elements fostering an engaged learning online scenario [25].

The literature provides us with many studies that have been proposed that awareness and emotions mechanisms are an important aspects to support learning. However, its implementation is not an easy task, due to it depends on many factors to facilitate a good communication among teachers and students. Research has shown that-in order to achieve successful, synchronous collaboration-users have to maintain knowledge about the interaction with other participants and the status of the shared resources. The solution proposed allow to help designers to integrate these awareness and emotion aspects into some online platforms. Just putting a group of people around a task does not guarantee a real and good collaboration, in that way it is necessary structure activities convey participation among group participants, and aspects related with age, number of people, and nature of task-among other elements—-need to be considered [26,27].

\section{Conclusions and Further Work}

The continued and growing need for new learning opportunities, linked with newer information systems and communication technologies, has pushed online learning into the center of the discussion of educational practice. Presenting information effectively is an important aspect in the teaching-learning process when we are working on e-learning and web platforms.

Aspects related with the quality of information allow building trust, based on the users' perception of the credibility of the application used. However, the online method of learning has certain challenges. Experts clarify that self-discipline is an important issue because students have the responsibility to complete the work and studies on time. Lack of information about what are they doing and how they interact with their classmates are important elements need to be considered. Despite many platforms offering different opportunities to support teaching-learning process on lockdown scenarios (due to COVID-19), many of them do not have essential aspects to offer a good communication between teachers and students. Aspects related with emotions and awareness have been manifested by teachers and students, in a survey performed in different Latin-American countries, as one of the most relevant elements need to be considered in online platforms supporting teaching-learning process. However, their inclusion is not an easy task. It is necessary to define what elements need to be include and are going to be presented to the users in order to have better communication mechanisms.

We have depicted a set of design guidelines recommendations to develop more usable web platforms supporting teaching-learning scenarios focused on aspects related with emotions and awareness. These guidelines could be implemented in different online 
platforms (commercial, open-source platforms) in order to improve communication and collaboration among teachers and students. We explored some web platforms following the suggested guidelines and evaluate the user experience of the software tools developed as future work. Also, we aim to include other elements into the design process like cognitive styles, context, learning activity, personal attributes.

Author Contributions: Conceptualization, C.A.C.; Data curation, C.S.P.; Visualization, H.F., D.A., C.S.P. and F.M.; Writing-original draft, C.A.C., H.F., D.A. and F.M.; Writing-review \& editing, C.A.C., H.F., D.A., C.S.P. and F.M. All authors have read and agreed to the published version of the manuscript.

Funding: This research received no external funding.

Institutional Review Board Statement: Ethical review and approval were waived for this study because all respondents were informed about the research's purpose and scope and were ensured their anonymity.

Informed Consent Statement: Not applicable because we are not working with patients.

Data Availability Statement: The data presented in this study are available on request from the corresponding author.

Conflicts of Interest: The authors declare no conflict of interest.

\section{References}

1. Kubala, T. Addressing Student's Needs: Teaching and Learning on the Internet. Online J. 1998, 25, 71-74.

2. Brunori, G.; Barjolle, D.; Dockes, A.-C.; Helmle, S.; Ingram, J.; Klerkx, L.; Moschitz, H.; Nemes, G.; Tisenkopfs, T. CAP Reform and Innovation: The Role of Learning and Innovation Networks. EuroChoices 2013, 12, 27-33. [CrossRef]

3. Luo, N.; Zhang, Y.; Zhang, M.L. Retaining learners by establishing harmonious relationships in e-learning environment. Interact. Learn. Environ. 2019, 27, 118-131. [CrossRef]

4. Weiss, J.; Hughes, J. Want collaboration? Accept and Actively Manage conflicts. Harv. Bus. Rev. 2005, 83, 92-101. [PubMed]

5. Ogan, A. Reframing Classroom Sensing: Promise and Peril. Interactions 2019, 26, 27-33. [CrossRef]

6. Collazos, C.; Guerrero, L.; Pino, J. Knowledge Construction Awareness. Stud. Cent. Learn. J. 2003, 1, 76-86.

7. Goldman, S.V. Computer resources for supporting student conversations about science concepts. SIGCUE Outlook 1992, 21, 4-7. [CrossRef]

8. Collazos, C.A.; Gutiérrez, F.L.; Gallardo, J.; Ortega, M.; Fardoun, H.M.; Molina, A.I. Descriptive theory of awareness for groupware development. J. Ambient Intell. Hum. Comput. 2019, 10, 4789-4818. [CrossRef]

9. Pekrun, R.; Goetz, T.; Frenzel, A.C.; Barchfeld, P.; Perry, R.P. Measuring emotions in students' learning and performance: The achievement emotions questionnaire (AEQ). Contemp. Educ. Psychol. 2011, 36, 36-48. [CrossRef]

10. Wolters, C.A. Regulation of Motivation: Evaluating an Underemphasized Aspect of Self-Regulated Learning. Educ. Psychol. 2003, 38, 189-205. [CrossRef]

11. Pekrun, R. Emotions as Drivers of Learning and Cognitive Development. In New Perspectives on Affect and Learning Technologies; Explorations in the Learning Sciences; Instructional Systems and Performance Technologies; Calvo, R., D’Mello, S., Eds.; Springer: New York, NY, USA, 2011; Volume 3, pp. 23-39.

12. Boekaerts, M. Motivation and self-regulation: Two close friends. In The Decade Ahead: Applications and Contexts of Motivation and Achievement; Urdan, T.C., Karabenick, S.A., Eds.; Emerald: Bingley, UK, 2010; pp. 69-108.

13. Boden, M.T.; Thompson, R.J. Facets of emotional awareness and associations with emotion regulation and depression. Emotion 2015, 15, 399-410. [CrossRef] [PubMed]

14. Calvo, R.A.; D'Mello, S. Affect detection: An Interdisciplinary review of models, methods, and their applications. IEEE Trans. Affect. Comput. 2010, 1, 18-37. [CrossRef]

15. Feidakis, M.; Daradoumis, T.; Caballé, S. Building emotion-aware features in Computer Supported Collaborative Learning (CSCL) systems. In Proceedings of the Alpine Rendez-Vous (ARV) Workshop on Tools and Technologies for Emotion Awareness in Computer-Mediated Collaboration and Learning (ARV 2013), Villard-de-Lans, France, 28 January-1 February 2013; TELEARC \& EATEL Associations: Villard-de-Lans, France, 2013.

16. Daradoumis, T.; Arguedas, M. Cultivating Students' Reflective Learning in Metacognitive Activities through an Affective Pedagogical Agent. Educ. Technol. Soc. 2020, 23, 19-31.

17. Arguedas, M.; Daradoumis, T.; Xhafa, F. Analyzing how emotion awareness influences students' motivation, engagement, self-regulation and learning outcome. Educ. Technol. Soc. 2016, 19, 87-103.

18. Shen, L.; Wang, M.; Shen, R. Affective e-learning: Using "emotional" data to improve learning in pervasive learning environment. Educ. Technol. Soc. 2009, 12, 176-189.

19. Lave, J.; Wenger, E. Situated Learning: Legitimate Peripheral Participation; Cambridge University Press: Cambridge, UK, 1991. 
20. Desmet, P.M.A. Design for mood: Twenty activity-based opportunities to design for mood regulation. Int. J. Des. 2015, 9, 1-19.

21. Ijsselsteijn, W.; Riva, G. Being There: The experience of presence in mediated environments. In Being There: Concepts, Effects and Measurement of User Presence in Synthetic Environments; Riva, G., Davide, F., Ijsselsteijn, W.A., Eds.; Ios Press: Amsterdam, The Netherlands, 2003; Volume 5, pp. 4-16.

22. Rodenstein, R.; Donat, J. Talking in Circles: A Spatially-grounde Social Environment. In Proceedings of the 2000 ACM Conference on Computer supported cooperative work, Philadelphia, PA, USA, 2-6 December 2000; Association for Computing Machinery: New York, NY, USA, 2000; pp. 81-88.

23. Borges, M.; Pino, J. Awareness Mechanisms for Coordination in Asynchronous CSCW. In Proceedings of the 9th Workshop on Information Technologies and Systems, Charlotte, NC, USA, 18-20 December 1999; pp. 69-74.

24. Henderson, D.A.; Card, S.K. Rooms: The Use of Multiple Virtual Workspaces to Reduce Space Contention. ACM Trans. Graph. 1985, 5, 211-243. [CrossRef]

25. Wang, M.J.; Kang, J. Cybergogy of engaged learning through information and communication technology: A framework for creating learner engagement. In Engaged Learning with Emerging Technologies; Hung, D., Khine, M.S., Eds.; Springer Publishing: New York, NY, USA, 2006; pp. 225-253.

26. Collazos, C.; Guerrero, L.; Pino, J.; Renzi, S.; Klobas, J.; Ortega, M.; Redondo, M.; Bravo, C. Evaluating collaborative learning processes using system-based measurement. Educ. Technol. Soc. 2007, 10, 257-274.

27. Agredo, V.; Collazos, C.; Fardoun, H.; Safa, N. Collaboration increase through monitoring and evaluation mechanisms of the collaborative learning process. In Proceedings of the International Conference on Social Computing and Social Media, Vancouver, BC, Canada, 15-20 July 2017; Springer Nature: Cham, Switzerland, 2017; pp. 20-31. 